\title{
Successful use of ofatumumab in two cases of early-onset juvenile SLE with thrombocytopenia caused by a mutation in protein kinase $C \delta$
}

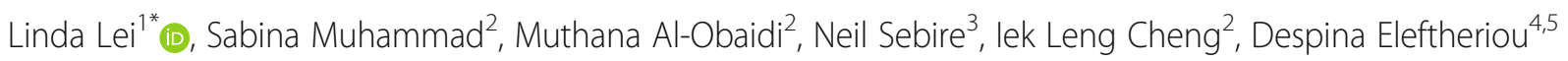
and Paul Brogan ${ }^{4}$

\begin{abstract}
Background: We previously described an endogamous Pakistani kindred in whom we identified a novel homozygous missense mutation in the PRKCD gene encoding for protein kinase $C \delta(P K C \delta)$ as a cause of monogenic systemic lupus erythematosus (SLE). PKC $\delta$ has a role in the negative regulation of B cells. Given the nature of the disease, a logical targeted therapeutic approach in these patients is B cell depletion. Indeed, the 3 siblings all had a marked clinical response and resolution of symptoms with rituximab, although 2 of the siblings had severe reactions to rituximab thus precluding further treatment with this. We therefore describe the first successful use of ofatumumab for this rare form of monogenic SLE.

Case presentation: All three affected siblings presented with SLE before the age of 3-years with lethargy, intermittent fever, thrombocytopenia, cutaneous involvement, alopecia, and hepatosplenomegaly. Tubulointerstitial nephritis was also present in 1 of the siblings. Homozygosity mapping followed by whole exome sequencing identified a homozygous missense mutation in PRKCD (p.Gly432Trp), subsequently confirmed by Sanger sequencing to be present in all 3 siblings. All 3 patients were initially treated with rituximab, however 2 of the siblings developed severe infusion-related reactions. For subsequent disease flare in these individuals we therefore used an alternative B cell depleting agent, ofatumumab (300 mg/1.73 $\mathrm{m}^{2}$ on day $1 ; 700 \mathrm{mg} / 1.73 \mathrm{~m}^{2}$ on day 15 ). This resulted in marked clinical improvement in both patients. To the best of our knowledge, this is the first report describing the successful use of ofatumumab for PKC $\delta$ deficiency.

Conclusions: PKC $\delta$ deficiency causes a monogenic form of SLE which responds well to B cell depletion. Ofatumumab is also likely to have a therapeutic role for sporadic juvenile SLE (jSLE) patients intolerant of rituximab.
\end{abstract}

Keywords: Ofatumumab, Juvenile SLE, Rituximab, Protein kinase C $\delta$ deficiency, Acute tubulointerstitial nephritis

\section{Background}

Juvenile SLE (jSLE) is rare before 5 years of age and can present with severe and atypical disease. There is an ever-expanding list of monogenic causes described, with a range of cutaneous and systemic features including cold-induced chilblain lupus, or mucocutaneous involvement, through to severe systemic and organ threatening manifestations such as renal involvement [1]. Awareness of monogenic forms of SLE is important, particularly for

\footnotetext{
* Correspondence: Lindalei93@gmail.com

'UCL Medical School, London, UK

Full list of author information is available at the end of the article
}

patients who present with SLE early in life. Moreover, there may be more targeted therapeutic options for such patients as compared to standard treatments for sporadic SLE [2]. The complexity in identifying a monogenic cause of lupus highlights the diagnostic importance of next generation sequencing (NGS) in this context, which can have major therapeutic and prognostic impact, in addition to facilitating family counselling. Indeed, the conventional approach of gene-by-gene testing by Sanger sequencing is increasingly superseded by NGS, particularly since there is a growing list of monogenic forms of SLE [2,3].

(c) The Author(s). 2018 Open Access This article is distributed under the terms of the Creative Commons Attribution 4.0 International License (http://creativecommons.org/licenses/by/4.0/), which permits unrestricted use, distribution, and 
We previously described an endogamous Pakistani kindred (Fig. 1a), with a homozygous missense mutation (p.Gly432Trp) in the PRKCD gene which codes for the active region of protein kinase $\mathrm{C} \delta(\mathrm{PKC} \delta)$ as a cause of monogenic SLE [4]. PRKCD is located on chromosome $3 \mathrm{p} 21.31$, and its protein product $\mathrm{PKC} \delta$ has a role in the negative regulation of $\mathrm{B}$ cells. Mice lacking in $\mathrm{PKC} \delta$ have expansion and dysregulation of $B$ cells [5], that might suggest a therapeutic role for $\mathrm{B}$ cell depletion in the human disease caused by PRKCD mutations. Herein we describe a novel disease manifestation of PKC $\delta$ deficiency, acute tubulointerstitial nephritis (TIN), and successful response to the B cell depleting agent ofatumumab in two of the siblings who developed hypersensitivity reactions to rituximab.

\section{Case presentation}

The pedigree is shown in Fig. 1a. The parents were first cousins. The first two siblings (II- 1 and II-2) became symptomatic at 12 months of age, and II-3 became symptomatic at 26 months of age. All three affected siblings (II-1, II-2, and II-3) presented with an SLE-like phenotype (Table 1) consisting of constitutional symptoms (intermittent fever, night sweats and fatigue), severe thrombocytopenia, cutaneous involvement, scarring alopecia, and hepatosplenomegaly. The cutaneous involvement in both siblings consisted of a photosensitive rash starting on the scalp and spreading to the malar area and nasal bridge with a petechial rash on the palms, soles, fingers and toes. II- 1 also had ulcers on her palate on an oral examination. II-2 had dilated nailfold capillaries on the fifth finger of her left hand. II-1 had a palpable spleen measuring $2-3 \mathrm{~cm}$ with palpable cervical lymphadenopathy (anterior and posterior chains) and inguinal lymphadenopathy. II-2 presented with a palpable liver edge and a palpable spleen measuring $2-3 \mathrm{~cm}$ with cervical and inguinal lymphadenopathy. There was no arthritis in both siblings. There was no abnormality detected in the cardiac or central nervous system for either II-1 or II-2, and they were both afebrile. A summary of immunological and other relevant investigations for all 3 siblings is provided in Tables 2 and 3. Based on the clinical and pathological results, the siblings fulfilled the classification criteria for SLE (Table 1). Homozygosity mapping followed by
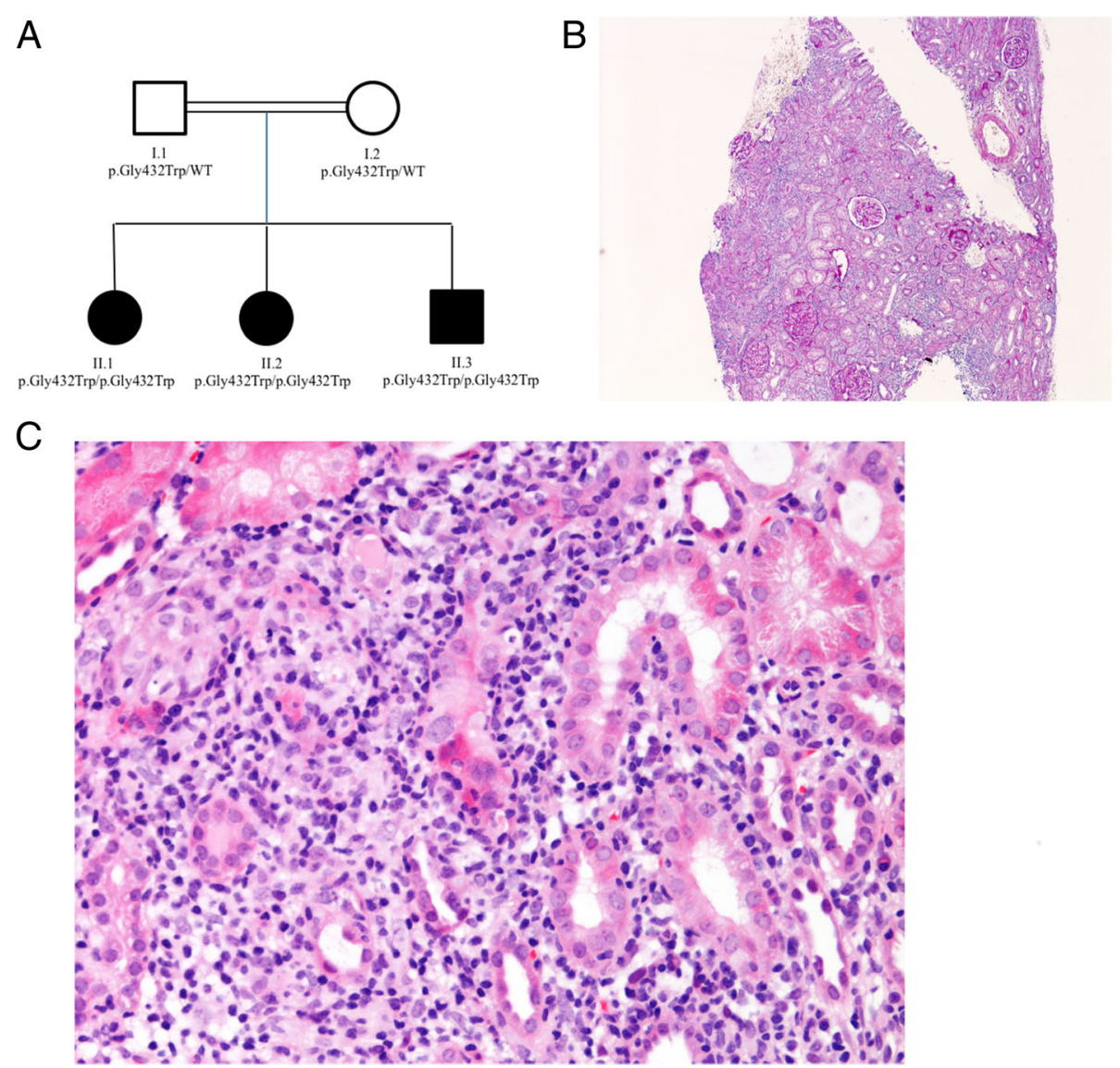

Fig. 1 Pedigree of the family and renal histology. a The affected siblings (shaded) are homozygous for the PRKCD mutation as indicated and the parents are carriers of the mutation. WT, wild type. $\mathbf{b}$ Low power (Periodic acid-Schiff stain, original magnification $\times 40$ ) and Fig. 1c higher power (Haematoxylin and Eosin stain, original magnification $\times 200$ ) showing severe acute tubulointerstitial nephritis with marked predominantly mononuclear inflammatory infiltrate and associated mild acute tubular damage 
Table 1 Systemic Lupus International Collaborating Clinics (SLICC) criteria and the presence $(\sqrt{ })$ or absence $(x)$ for each affected sibling [25]

\begin{tabular}{|c|c|c|c|}
\hline & $\|-1$ & $\|-2$ & $11-3$ \\
\hline Acute cutaneous lupus & $\sqrt{ }$ & $\sqrt{ }$ & $\sqrt{ }$ \\
\hline Chronic cutaneous lupus & $x$ & $x$ & $x$ \\
\hline Oral or nasal ulcers & $\sqrt{ }$ & $x$ & $x$ \\
\hline Non-scarring alopecia & $\sqrt{ }$ & $\sqrt{ }$ & $\sqrt{ }$ \\
\hline Arthritis & $x$ & $x$ & $x$ \\
\hline Serositis & $x$ & $\sqrt{ }$ & $x$ \\
\hline Renal & $x$ & $\sqrt{ }$ & $x$ \\
\hline Neurologic & $x$ & $x$ & $x$ \\
\hline Haemolytic anaemia & $\sqrt{ }$ & $\sqrt{ }$ & $\sqrt{ }$ \\
\hline Leukopenia & $\sqrt{ }$ & $\sqrt{ }$ & $x$ \\
\hline Thrombocytopenia & $\sqrt{ }$ & $\sqrt{ }$ & $\sqrt{ }$ \\
\hline ANA (above lab range) & $\sqrt{ }$ & $\sqrt{ }$ & $\sqrt{ }$ \\
\hline Anti-dsDNA(above lab range) & $\sqrt{ }$ & $\sqrt{ }$ & $\sqrt{ }$ \\
\hline Anti-Sm & $x$ & $x$ & $\sqrt{ }$ \\
\hline Anti-phospholipid antibody & $\sqrt{ }$ & $\sqrt{ }$ & $x$ \\
\hline Low complement & $\sqrt{ }$ & $\sqrt{ }$ & $\sqrt{ }$ \\
\hline Direct Coombs' test & not assessed & not assessed & not assessed \\
\hline
\end{tabular}

WCC White cell count, ANA Anti-nuclear antibodies, ds-DNA Double-stranded deoxyribonucleic acid, $\mathrm{Sm}$ Smith. To fulfil these classification criteria, 4 or more criteria must be present (including at least one clinical and one immunological feature), or biopsy proven lupus nephritis with positive ANA or anti-DNA antibodies

whole exome sequencing identified a homozygous missense mutation (p.Gly432Trp) in PRKCD in II-1 and II-2, subsequently confirmed by Sanger sequencing to be present in all 3 siblings (Fig. 1a). Full details regarding the methodology for the various gene screening strategies are available elsewhere [4].

In addition to the investigations included in Tables 1,2 and 3, additional autoimmune workup in II- 1 at the time of initial presentation revealed: IgA $2.20 \mathrm{G} / \mathrm{L}$ (RR 0.4-2.0), tissue transglutaminase (TTG) IgA screening negative, C1q
18.0 U/ml (RR 0-15), C1 esterase inhibitor $438.0 \mathrm{mg} / \mathrm{L}$ (RR 150-350), C1 esterase functional assay $>93 \%$ (RR > 84\%), C1q level $53.0 \mathrm{mg} / \mathrm{L}$ (RR 50-250), proteinase 3 antineutrophil cytoplasmic antibodies (PR3-ANCA) $0.40 \mathrm{IU} / \mathrm{ml}$ (RR 0-1.99), myeloperoxidase (MPO) ANCA $0.40 \mathrm{IU} / \mathrm{ml}$ (RR 0-3.49), rheumatoid factor $<0.20 \mathrm{IU} / \mathrm{ml}$ (RR 0. 20), thyroid peroxidase antibodies $<33.4 \mathrm{IU} / \mathrm{ml}(\mathrm{RR}<60)$, classical and alternative functional complement assays were normal at $110 \%(R R>40)$ and $92 \%(R R>10)$ respectively.

Full autoimmune workup (see also Tables 1,2 and 3) for II-2 revealed: IgA 2.88 G/L (RR 0.4-2.0), TTG IgA screening negative, C1q $9.0 \mathrm{U} / \mathrm{ml}$ (RR 0-15), C1 esterase inhibitor $434.0 \mathrm{mg} / \mathrm{L}$ (RR 150-350), C1 esterase functional assay > 93\% (RR > 84\%), C1q level $42.0 \mathrm{mg} / \mathrm{L}$ (RR 50-250), PR3-ANCA $0.60 \mathrm{IU} / \mathrm{ml}$ (RR 0-1.99), MPO-ANCA $0.80 \mathrm{IU} / \mathrm{ml}$ (RR $0-3.49$ ), rheumatoid factor $<0.20 \mathrm{IU} / \mathrm{ml}$ (RR 0. 20), thyroid peroxidase antibodies $<33.4 \mathrm{IU} / \mathrm{ml}$ $(\mathrm{RR}<60)$, and normal classical and alternative complement functional pathway assay at $75 \%(\mathrm{RR}>40)$ and 99\% (RR > 10) respectively.

ENA antibody typing was also done for II- 1 and II-2 at presentation, at time of relapse and at 8 months follow-up after ofatumumab (Table 2). ASMA and anti-LKM autoantibodies were not assessed.

II-1 and II-2 failed initial treatment with high dose corticosteroids, hydroxychloroquine $5 \mathrm{mg} / \mathrm{kg}$ per day and azathioprine $2 \mathrm{mg} / \mathrm{kg}$ per day. II-2 developed spontaneous gingival bleeding, and platelet-count $4 \times 10^{\wedge} 9 / \mathrm{L}$ (reference range [RR]150-450). Following IVIG $2 \mathrm{~g} / \mathrm{kg}$, platelets rose transiently to $30 \times 10^{\wedge} 9 / \mathrm{L}$. Consequently, she received rituximab $\left(750 \mathrm{mg} / \mathrm{m}^{2}\right.$ (maximum $1 \mathrm{~g}$ ) on day 1 and $15)$. The platelet count rapidly normalised $\left(179 \times 10^{\wedge} 9 /\right.$ L), with near-normalization of other laboratory parameters [6]. However, during the second rituximab infusion she developed urticaria, wheeze, and hypotension despite premedication, necessitating discontinuation of the infusion discontinuation, and treatment with hydrocortisone and volume expansion with normal saline. Despite that, she had a good therapeutic response and adequate B cell depletion (peripheral blood CD19 count less than 1\%).

Table 2 Extractable nuclear antigen (ENA) antibody typing for siblings II-1 and I-2 at initial presentation, at relapse of disease and 8 months after ofatumumab

\begin{tabular}{|c|c|c|c|c|c|c|}
\hline \multirow[t]{2}{*}{ ENA antibody typing } & \multicolumn{3}{|l|}{ Patient II-1 } & \multicolumn{3}{|l|}{ Patient II-2 } \\
\hline & At presentation & At relapse & 8 months after ofatumumab & At presentation & At relapse & 8 months after ofatumumab \\
\hline anti-NRNP & negative & negative & positive & negative & negative & equivocal \\
\hline anti-SME & negative & negative & positive & negative & negative & positive \\
\hline anti-Ro & negative & negative & positive & negative & negative & negative \\
\hline anti-La & negative & negative & negative & negative & negative & negative \\
\hline anti-Jo-1 & negative & negative & negative & negative & negative & negative \\
\hline anti-Scl70 & negative & negative & negative & negative & negative & negative \\
\hline other ENA antibodies & weakly positive & negative & negative & weakly positive & negative & negative \\
\hline
\end{tabular}


Table 3 Laboratory data of siblings II-1 and II-2 at initial presentation, at relapse of disease requiring ofatumumab infusion and at follow-up 8 months after ofatumumab infusion

\begin{tabular}{|c|c|c|c|c|c|c|}
\hline \multirow[t]{2}{*}{ Investigations } & \multicolumn{3}{|c|}{ Patient II-1 (reference range) } & \multicolumn{3}{|c|}{ Patient II-2 (reference range) } \\
\hline & At presentation & At relapse & $\begin{array}{l}8 \text { months after } \\
\text { ofatumumab }\end{array}$ & At presentation & At relapse & $\begin{array}{l}8 \text { months after } \\
\text { ofatumumab }\end{array}$ \\
\hline $\mathrm{FBC} \times 10^{\wedge} 12 / \mathrm{L}(\mathrm{RR} 4.00-5.20)$ & 3.88 & 3.92 & 4.76 & 3.6 & 3.01 & 5.26 \\
\hline $\mathrm{Hb}$ g/L (RR 115-145) & 96 & 102 & 118 & 97 & 73 & 128 \\
\hline Platelets × 10^9/L (RR 150-450) & 85 & 5 & 209 & 13 & 63 & 397 \\
\hline WCC $\times 10 \wedge 9 / L(R R$ 0.0-10.0) & 5.94 & 6.54 & 6.58 & 9.60 & 2.78 & 7.83 \\
\hline Lymphocytes × 10^9/L (1.5-7.0) & 1.79 & 1.69 & 1.65 & 1.70 & 0.48 & 1.86 \\
\hline Neutrophils × 10^9/L (RR 1.5-8.0) & 2.17 & 4.20 & 1.83 & 1.01 & 2.23 & 4.90 \\
\hline CD 19 lymphocyte subset \% & 21.0 & not assessed & 0.0 & 25.0 & 23.7 & 0.5 \\
\hline CD 3 lymphocyte subset \% & 73.0 & not assessed & 97.5 & 65.0 & 83.0 & 96.0 \\
\hline CD 16+ CD 56+ lymphocyte subset \% & 4.0 & not assessed & 1.7 & 8.0 & 5.0 & 0.7 \\
\hline CD 3+ CD 56+ lymphocyte subset \% & 0.2 & not assessed & not assessed & 0.2 & 0.8 & not assessed \\
\hline CD 3+ CD4+ lymphocyte subset \% & 46.0 & not assessed & 49.7 & 32.0 & 38.0 & 41.5 \\
\hline CD 3+ CD 8+ lymphocyte subset \% & 21.0 & not assessed & 40.6 & 37.0 & 37.0 & 42.2 \\
\hline ESR mm/hr. (RR 0-10) & 128 & 132 & 50 & 130 & 75 & 1 \\
\hline CRP mg/L (RR < 20) & 21 & 19 & $<5$ & 28 & 21 & $<5$ \\
\hline Urea & 3.4 & 3.9 & 3.4 & 4.8 & 7.8 & 4.1 \\
\hline Creatinine umol/L (RR 28-57) & 36 & 25 & 40 & 33 & 83 & 52 \\
\hline Urine creatinine $\mathrm{mmol} / \mathrm{L}$ & 3.4 & 1.5 & 3.5 & 2.8 & 1.1 & 0.5 \\
\hline Urine albumin/creatinine ratio mg/mmol (RR 0.2-4.5) & 1.5 & 5.3 & 3.1 & 8.9 & 1.1 & not assessed \\
\hline Urine NAG/creatinine ratio units/mmol (RR 2-20) & not assessed & not assessed & 4 & not assessed & 67 & 74 \\
\hline Urine retinol binding protein ug/L & not assessed & not assessed & 39 & not assessed & not assessed & 161 \\
\hline Urine retinol/creatinine ratio ug/mmol (RR 5-41) & not assessed & not assessed & 11 & not assessed & not assessed & 85 \\
\hline ANA & $1: 1280$ & not assessed & $1: 640$ & Negative & not assessed & not assessed \\
\hline Anti-DNA IU/ml (RR 0-9.9) & 65 & 66 & 16 & 43 & 16 & 4.8 \\
\hline IgG G/L (RR 5.4-16.1) & 16.8 & 22.3 & 7.66 & 21.9 & 18.5 & 7.12 \\
\hline $\operatorname{lgA}$ G/L (RR 0.5-2.4) & 2.19 & 2.35 & 1.15 & 2.69 & 3.34 & 1.72 \\
\hline $\operatorname{lgM}$ G/L (RR 0.5-1.8) & 1.63 & 1.31 & 0.35 & 2.90 & 2.36 & 0.86 \\
\hline C3 G/L (RR 0.75-1.65) & 0.83 & 0.41 & 1.51 & 0.64 & 0.91 & 1.37 \\
\hline C4 G/L (RR 0.14-0.54) & 0.10 & 0.03 & 0.19 & 0.08 & 0.15 & 0.29 \\
\hline
\end{tabular}

$R R$ Reference range, FBC Full blood count, $\mathrm{Hb}$ haemoglobin, WCC White cell count, ESR Erythrocyte sedimentation rate, CRP C reactive protein, NAG Nitrosaminoglycan, DNA deoxyribonucleic acid

Twelve months later, II-2 was re-admitted with lethargy, poor appetite, night sweats and was found to have renal impairment, ongoing acute phase response, and return of B cells (CD19 23.7\%): blood pressure 102/43 mm/ Hg; urea $7.8 \mathrm{mmol} / \mathrm{L}$ (RR 2.5-6.0); creatinine $83 \mu \mathrm{mol} / \mathrm{L}$ (RR 3048); and ESR $75 \mathrm{~mm} / \mathrm{hr}$. (RR 0.0-10.0). Urinary chemistry was consistent with tubulopathy: urine $\left({ }_{u}\right)$ sodium $122 \mathrm{mmol} / \mathrm{l}$, u-potassium $36 \mathrm{mmol} / \mathrm{L}$, ${ }_{u} \mathrm{pH}$ 7.0, ${ }_{\mathrm{u}}$ nitrosaminoglycan [NAG]/creatinine ratio 67 (RR 2-20), u-albumin/ creatinine ratio $1.1 \mathrm{mg} / \mathrm{mmol}$ (RR 0.2-4.5). Renal biopsy confirmed acute tubulointerstitial nephritis, with coexistent chronic changes (Fig. 1b, and c). She received IV methylprednisolone $(30 \mathrm{mg} / \mathrm{kg})$ for 3 days, thereafter continuing on a tapering course of prednisolone $40 \mathrm{mg} /$ day. In view of her genotype and excellent previous therapeutic response (but severe drug reaction) to rituximab, ofatumumab $\left(300 \mathrm{mg} / 1.73 \mathrm{~m}^{2}\right.$ on day $1 ; 700 \mathrm{mg} / 1.73 \mathrm{~m}^{2}$ on day 15) was commenced. Again, B cells depleted successfully (CD19: 0.1\%), and her lethargy, poor appetite, and night sweats had resolved completely two weeks later. At follow-up eight months later, her renal function had improved (urea $4.1 \mathrm{mmol} / \mathrm{L}$; creatinine $52 \mu \mathrm{mol} / \mathrm{L}$ ) allowing successful prednisolone taper; but tubular function was not completely normal ${ }_{\mathrm{u}} \mathrm{NAG}$-creatinine ratio 74 ), indicating that the chronic changes identified on renal biopsy may be irreversible, and not amenable to improvement with immunosuppressive treatment. At follow-up eight months after ofatumumab infusion, B cells were still 
only gradually recovering (CD19 0.5\%) (Table 3). In terms of the antibodies, anti-dsDNA antibodies was $16 \mathrm{IU} / \mathrm{ml}$ (RR 0-9.9) at the time of relapse and this dropped to 4.8 IU/ml (RR 0-9.9) eight months after ofatumumab infusion (Table 3). Hb recovered from $73 \mathrm{~g} / \mathrm{L}$ (RR 115-145) to $128 \mathrm{~g} / \mathrm{L}$ (RR 115-145), and the white cell count also improved from $2.78 \times 10^{\wedge} 9 / \mathrm{L}$ (RR 5.0-15.0) to $7.83 \times 10^{\wedge} 9 / \mathrm{L}$ (RR 5.0-15.0) (Table 3). At follow-up eight months after ofatumumab infusion, there are no adverse events reported.

A similar story gradually evolved in II-1. Although the symptoms (thrombocytopenia, rash, and alopecia) initially responded to a first course of rituximab ( 2 infusions of $750 \mathrm{mg} / \mathrm{m}^{2}$, on day 1 and 15 ), return of these symptoms, plus increasing lethargy and night sweats within a year indicated the need for retreatment. During the second of two planned rituximab infusions, she developed severe diffuse cutaneous erythema and tachycardia necessitating infusion discontinuation, although again she still adequately B cell depleted and had symptomatic relief for 32 months. She then re-presented with platelets of $5 \times 10^{9} / \mathrm{L}$, and thus received ofatumumab (same dose as for patient II-2) without incident. Her platelet count rapidly rose to $209 \times 10^{9} / \mathrm{L}$, with sustained therapeutic response and B cell depletion (CD19 0.0\%) now 8 months later. At follow-up, the cutaneous symptoms had resolved in both II-1 and II-2 although the scarring alopecia is more likely to be chronic. The hepatosplenomegaly, lethargy and night sweats had also resolved. II -2 has kidney involvement that is likely to be chronic. In terms of the serological response, anti-dsDNA antibodies was $66 \mathrm{IU} / \mathrm{ml}$ (RR 0-9.9) at the time of relapse and this dropped to $16 \mathrm{IU} / \mathrm{ml}$ (RR 0-9.9) eight months after ofatumumab infusion (Table 3 ). Hb improved from $102 \mathrm{~g} / \mathrm{L}$ (RR 115-145) to $118 \mathrm{~g} / \mathrm{L}$ (RR 115-145) (Table 3). At follow-up eight months after ofatumumab infusion, there are no adverse events reported.

II-3 developed symptoms at age 26 months: facial rash, alopecia, and platelets $6 \times 10^{9} / \mathrm{L}$. He required IV methylprednisolone, IVIG $2 \mathrm{~g} / \mathrm{Kg}$, and two infusions of rituximab which he received without incident and with sustained efficacy at last follow-up despite return of B cells (CD19 $0.1 \%$ post rituximab; 9.4\%) 8 months after receiving rituximab.

\section{Discussion and conclusions}

This report emphasises a number of novel observations: firstly, severe recalcitrant thrombocytopenia is a prominent feature of PKC $\delta$ deficiency; secondly, we provide the first description of acute TIN associated with PKC $\delta$ deficiency; thirdly, PKC $\delta$ deficiency is exquisitely sensitive to $B$ cell depletion (with no obvious difference in efficacy between rituximab or Ofatumumab, notwithstanding the issues of hypersensitivity); and lastly, 2 of the siblings suffered intolerable infusion reactions to rituximab, but have so far responded well to ofatumumab, which may offer a less immunogenic alternative for patients with prior rituximab hypersensitivity.

PKC $\delta$ has been ascribed critical roles in the regulation of cellular proliferation and apoptosis, with important pro-apoptotic activity due to the inhibition of cell cycle progression [7]. PKC $\delta$-driven apoptosis has also been reported in association with various DNA damaging agents, such as UV radiation and etoposide $[6,8,9]$. PKC $\delta$ regulates $\mathrm{B}$ cell negative selection, and deficiency of $\mathrm{PKC} \delta$ causes systemic autoimmunity in mice [10], and also in humans with phenotypes that include lymphoproliferative disease and lupus-like autoimmunity [4, 11]. Belot et al. described 3 siblings from a consanguineous kindred with an increased number of immature B cells and a developmental shift towards naïve $B$ cells with an immature phenotype, indicating that $\mathrm{PKC} \delta$ is vital in regulating $\mathrm{B}$ cell maturation and tolerance [11], (and see Table 4). These observations almost certainly explain why autoimmunity in humans caused by $\mathrm{PKC} \delta$ deficiency seems particularly amenable to treatments that target B lymphocytes, as illustrated by the kindred described herein.

Ofatumumab is a fully human monoclonal antibody targeting $\mathrm{B}$ cells that may provide an attractive alternative to rituximab since it can deplete rituximab-resistant cells that express low levels of CD20, possibly through targeting a different epitope of CD20 [12], or by increased complement-dependent cytotoxicity [13]. The first ofatumumab clinical trial in 2008 was in patients with refractory or relapsed chronic lymphocytic leukaemia, leading to Federal Drug Agency approval for this indication in 2009. Ofatumumab has since been used for various conditions including nephrotic syndrome, refractory follicular lymphoma, and multiple sclerosis [14-16], amongst others. Several trials have highlighted a potential role for ofatumumab in diseases that are refractory to conventional treatment. For example, in biological-naïve rheumatoid arthritis with an inadequate response to methotrexate, patients on ofatumumab had significantly improved clinical outcomes without detectable immunogenicity [17]. In comparison to rituximab, which is a chimeric antibody, ofatumumab is a fully humanised monoclonal antibody (generated via human immunoglobulin transgenic mice) which may explain this reduced immunogenicity, and perhaps why this was better tolerated than rituximab in our two patients.

Although rituximab did not demonstrate efficacy in clinical trials of patients with SLE (probably due to trial methodological considerations), there is an increasingly compelling real-world evidence base for the efficacy of $\mathrm{B}$ cell depletion with rituximab in patients with refractory SLE [18]. That said, severe infusion reactions are commonly reported and therefore alternative B cell depleting agents may be required. The first report of ofatumumab in SLE was in an adult in 2014 [19]; in addition, there 


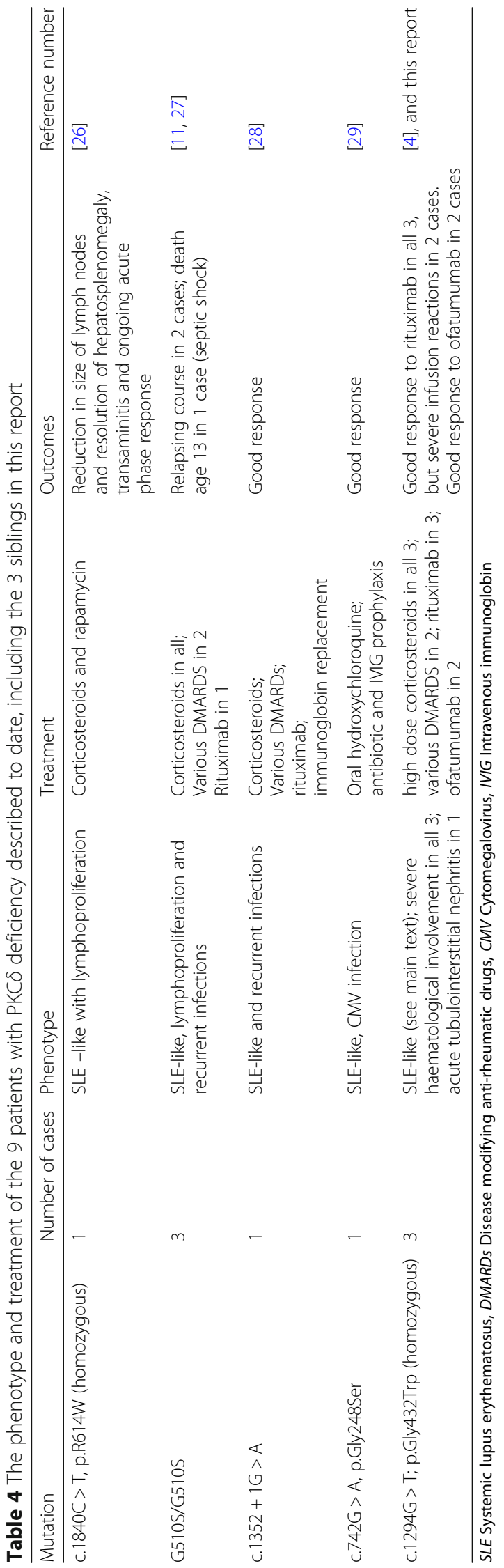


has been a single report of its use in jSLE, where it was used successfully to treat a 20 year old with recalcitrant life-threatening autoimmune haemolytic anaemia (AIHA) [20]. This patient had also failed multiple drugs, and had also experienced a severe infusion reaction to rituximab [20]. The dose we used $\left(300 \mathrm{mg} / 1.73 \mathrm{~m}^{2}\right.$ on day $1 ; 700 \mathrm{mg} /$ $1.73 \mathrm{~m}^{2}$ on day 15) was the same low-dose protocol as described by Bonnani [21] for nephrotic syndrome, but lower than that previously used in other reports for idiopathic nephrotic syndrome [22]. Both II-1 and II-2 have had an improvement in their symptoms following ofatumumab, including improvement (but not normalisation) of renal function in II-2.

The main limitations of our observations thus far are limited time to follow-up; and lack of detailed B cell immunophenotyping pre and post B cell depletion, since samples were not available to us for these studies. We anticipate an ongoing relapsing disease course with return of B cells. Therapeutic options beyond B cell depletion are extremely limited, although there could be a role for other B cell-targeting biologics. Ultimately, however, allogeneic haematopoietic stem cell transplantation may be required, although this has never been reported for PKC $\delta$ deficiency (Table 4). Autologous HSCT, although potentially less toxic than allogeneic and emerging as a possible treatment for severe SLE [23, 24], is unlikely to be a useful therapeutic option for this monogenic form of SLE.

In conclusion, we describe the first favourable report of the use of ofatumumab for the treatment of monogenic lupus caused by PKC $\delta$ deficiency. Ofatumumab could also have a role for sporadic jSLE patients intolerant of rituximab.

\section{Abbreviations}

jSLE : juvenile SLE; PKC 8 : Protein kinase C $\delta$; SLE: Systemic lupus erythematosus

\section{Availability of data and materials}

All data generated or analysed during this study are included in this published article.

\section{Authors' contributions}

$\mathrm{LL}, \mathrm{SM}, \mathrm{MO}, \mathrm{DE}$ and PB contributed conception and design of the study. $\mathrm{LL}$ wrote the first draft of the manuscript. LL, IC, DE and PB wrote sections of the manuscript. NS contributed the histopathological tests and findings. All authors contributed to manuscript revision, read and approved the submitted version.

\section{Ethics approval and consent to participate}

This study was performed with ethical approval and consent from all included in the study.

\section{Consent for publication}

Written informed consent for publication was obtained from all included in the study.

\section{Competing interests}

DE has institutional grants from Pfizer and Lilly. PB received consultancy fees from Roche and SOBI, institutional grants from Roche, SOBI and Novartis, and speaker fees from UCB. The other authors have declared no competing interests.

\section{Publisher's Note}

Springer Nature remains neutral with regard to jurisdictional claims in published maps and institutional affiliations.

\section{Author details}

${ }^{1}$ UCL Medical School, London, UK. ${ }^{2}$ Paediatric Rheumatology Department, Great Ormond Street Hospital for Children NHS Trust, London, UK. ${ }^{3}$ Department of Paediatric Histopathology, Great Ormond Street Hospital, London, UK. ${ }^{4}$ Infection, Inflammation and Rheumatology Section, Infection, Immunity, Inflammation and Physiological Medicine Programme, UCL Institute of Child Health, London, UK. ${ }^{5}$ ARUK centre for adolescent rheumatology, London, UK.

Received: 19 March 2018 Accepted: 18 September 2018

Published online: 26 September 2018

\section{References}

1. Costa-Reis P, Sullivan KE. Monogenic lupus: it's all new! Curr Opin Immunol. 2017:49:87-95.

2. Omoyinmi E, Standing A, Keylock A, Price-Kuehne F, Melo Gomes S, Rowczenio D, et al. Clinical impact of a targeted next-generation sequencing gene panel for autoinflammation and vasculitis. PLoS One. 2017;12(7):e0181874

3. Belot A, Cimaz R. Monogenic forms of systemic lupus erythematosus: new insights into SLE pathogenesis. Pediatr Rheumatol Online J. 2012;10(1):21.

4. Nanthapisal S, Omoyinmi E, Murphy C, Standing A, Eisenhut M, Eleftheriou D, Brogan PA. Early-Onset Juvenile SLE Associated With a Novel Mutation in Protein Kinase C S. Pediatrics. 2017;139(1). Article E20160781.

5. Akitomo M, Keiko N, Hiroyuki I, Sachiko H, Yi J, Masaaki A, et al. Increased proliferation of $B$ cells and auto-immunity in mice lacking protein kinase $C \delta$. Nature. 2002;416(6883):865

6. Watanabe T, Ono Y, Taniyama Y, Hazama K, Igarashi K, Ogita K, et al. Cell division arrest induced by phorbol ester in $\mathrm{CHO}$ cells overexpressing protein kinase C-delta subspecies. Proc Natl Acad Sci U S A. 1992;89(21):10159-63.

7. Reyland ME. Protein kinase Cdelta and apoptosis. Biochem Soc Trans. 2007;35(Pt 5):1001-4.

8. Denning MF, Wang Y, Tibudan S, Alkan S, Nickoloff BJ, Qin JZ. Caspase activation and disruption of mitochondrial membrane potential during UV radiation-induced apoptosis of human keratinocytes requires activation of protein kinase C. Cell Death Differ. 2002;9(1):40-52.

9. Lomonaco SL, Kahana S, Blass M, Brody Y, Okhrimenko H, Xiang C, et al. Phosphorylation of protein kinase Cdelta on distinct tyrosine residues induces sustained activation of Erk1/2 via down-regulation of MKP-1: role in the apoptotic effect of etoposide. J Biol Chem. 2008;283(25):17731-9.

10. Miyamoto A, Nakayama K, Imaki H, Hirose S, Jiang Y, Abe M, et al. Increased proliferation of $B$ cells and auto-immunity in mice lacking protein kinase Cdelta. Nature. 2002;416(6883):865-9.

11. Belot A, Kasher PR, Trotter EW, Foray AP, Debaud AL, Rice Gl, et al. Protein kinase $c \delta$ deficiency causes mendelian systemic lupus erythematosus with $B$ cell-defective apoptosis and hyperproliferation. Arthritis Rheum. 2013;65(8): 2161-71.

12. Keating MJ, Dritselis A, Yasothan U, Kirkpatrick P. Ofatumumab. Nat Rev Drug Discov. 2010;9(2):101-2.

13. Teeling JL, French RR, Cragg MS, van den Brakel J, Pluyter M, Huang H, et al. Characterization of new human CD20 monoclonal antibodies with potent cytolytic activity against non-Hodgkin lymphomas. Blood. 2004;104(6):1793-800.

14. Sorensen PS, Lisby S, Grove R, Derosier F, Shackelford S, Havrdova E, et al. Safety and efficacy of ofatumumab in relapsing-remitting multiple sclerosis: a phase 2 study. Neurology. 2014;82(7):573-81.

15. Hagenbeek A, Gadeberg O, Johnson P, Pedersen LM, Walewski J, Hellmann $A$, et al. First clinical use of ofatumumab, a novel fully human anti-CD20 monoclonal antibody in relapsed or refractory follicular lymphoma: results of a phase 1/2 trial. Blood. 2008;111(12):5486-95

16. Coiffier B, Lepretre S, Pedersen LM, Gadeberg O, Fredriksen H, van Oers MH, et al. Safety and efficacy of ofatumumab, a fully human monoclonal antiCD20 antibody, in patients with relapsed or refractory B-cell chronic lymphocytic leukemia: a phase 1-2 study. Blood. 2008:111(3):1094-100.

17. Taylor PC, Quattrocchi E, Mallett S, Kurrasch R, Petersen J, Chang DJ. Ofatumumab, a fully human anti-CD20 monoclonal antibody, in biologicalnaive, rheumatoid arthritis patients with an inadequate response to 
methotrexate: a randomised, double-blind, placebo-controlled clinical trial. Ann Rheum Dis. 2011;70(12):2119-25.

18. McCarthy EM, Sutton E, Nesbit S, White J, Parker B, Jayne D, et al. Short-term efficacy and safety of rituximab therapy in refractory systemic lupus erythematosus: results from the British Isles lupus assessment group biologics register. Rheumatology (Oxford). 2018;57(3):470-9.

19. Thornton CC, Ambrose N, loannou Y. Ofatumumab: a novel treatment for severe systemic lupus erythematosus. Rheumatology (Oxford). 2015;54(3): 559-60.

20. Karageorgas T, Zomas A, Kazakou P, Katsimbri P, Mantzourani M, Boumpas D. Successful treatment of life-threatening autoimmune haemolytic anaemia with ofatumumab in a patient with systemic lupus erythematosus. Rheumatology (Oxford). 2016;55(11):2085-7.

21. Bonanni A, Rossi R, Murtas C, Ghiggeri GM. Low-dose ofatumumab for rituximab-resistant nephrotic syndrome. BMJ Case Rep. 2015;2015.

22. Vivarelli M, Colucci M, Bonanni A, Verzani M, Serafinelli J, Emma F, et al. Ofatumumab in two pediatric nephrotic syndrome patients allergic to rituximab. Pediatr Nephrol. 2017;32(1):181-4.

23. Alchi B, Jayne D, Labopin M, Demin A, Sergeevicheva V, Alexander T, et al. Autologous haematopoietic stem cell transplantation for systemic lupus erythematosus: data from the European Group for Blood and Marrow Transplantation registry. Lupus. 2013:22(3):245-53.

24. Jayne D, Passweg J, Marmont A, Farge D, Zhao X, Arnold R, et al. Autologous stem cell transplantation for systemic lupus erythematosus. Lupus. 2004;13(3):168-76.

25. Petri M, Orbai AM, Alarcón GS, Gordon C, Merrill JT, Fortin PR, et al. Derivation and validation of the systemic lupus international collaborating clinics classification criteria for systemic lupus erythematosus. Arthritis Rheum. 2012;64(8):2677-86.

26. Kuehn HS, Niemela JE, Rangel-Santos A, Zhang M, Pittaluga S, Stoddard JL, et al. Loss-of-function of the protein kinase C $\delta$ (PKC $)$ causes a B-cell lymphoproliferative syndrome in humans. Blood. 2013;121(16):3117-25.

27. Andre J, Cimaz R, Ranchin B, Galambrun C, Bertrand Y, Bouvier R, et al. Overexpression of the antiapoptotic gene Bfl-1 in B cells from patients with familial systemic lupus erythematosus. Lupus. 2007;16(2):95-100.

28. Salzer E, Santos-Valente E, Klaver S, Ban SA, Emminger W, Prengemann NK et al. B-cell deficiency and severe autoimmunity caused by deficiency of protein kinase C $\delta$. Blood. 2013;121(16):3112-6.

29. Kiykim A, Ogulur I, Baris S, Salzer E, Karakoc-Aydiner E, Ozen AO, et al. Potentially beneficial effect of hydroxychloroquine in a patient with a novel mutation in protein kinase C $\delta$ deficiency. J Clin Immunol. 2015;35(6):523-6.

Ready to submit your research? Choose BMC and benefit from:

- fast, convenient online submission

- thorough peer review by experienced researchers in your field

- rapid publication on acceptance

- support for research data, including large and complex data types

- gold Open Access which fosters wider collaboration and increased citations

- maximum visibility for your research: over $100 \mathrm{M}$ website views per year

At $\mathrm{BMC}$, research is always in progress.

Learn more biomedcentral.com/submissions 